\title{
ROLE OF WEIGHT REDUCTION AND ITS SIGNIFICANCE IN RESTORING FERTILITY - IN OBESE AND OVERWEIGHT WOMEN
}

Sucheta Mukherjee ${ }^{1}$, Lovely Agarwal2 ${ }^{2}$ Mrinal Kanti Biswas³ ${ }^{3}$ Debilina Roy ${ }^{4}$

\section{HOW TO CITE THIS ARTICLE:}

Sucheta Mukherjee, Lovely Agarwal, Mrinal Kanti Biswas, Debilina Roy. "Role of Weight Reduction and its significance in Restoring Fertility - in Obese and Overweight Women". Journal of Evolution of Medical and Dental Sciences 2014; Vol. 3, Issue 05, February 03; Page: 1245-1249, DOI: 10.14260/jemds/2014/1976

ABSTRACT: OBJECTIVE: To assess the role of obesity (in terms of body mass index) on female fertility. Methods- A prospective study of 62 obese women over a period of 2 years from June 2009 to May 2011 at Calcutta National Medical Colleg e was done. RESULTS: Fertility regained in 25.72\% after weight reduction. Estimated success probability equals 0.2592 . P value was statistically significant. Weight reduction of $7-10 \mathrm{kgs}$ of body weight was achieved in $62.5 \%$ patients. CONCLUSION: Weight reduction is the appropriate treatment for women with obesity related infertility.

KEYWORDS: Body mass index (BMI), obesity, infertility.

INTRODUCTION: Obesity has become a worldwide epidemic with ever increasing incidence and public health problem in both developing and developed countries ${ }^{1}$. In obese women, the rate of complications during pregnancy and delivery and the prevalence of gynecological tumors like endometrial or breast cancer is higher ${ }^{2}$. Obesity is also associated with infertility and menstrual irregularity ${ }^{3}$. Recent data suggest that overweight and obese patients are also at increased risk of recurrent pregnancy loss (RPL) that affects $1 \%$ of the fertile population ${ }^{4}$. Obesity is measured by body mass index (BMI) which is the ratio of weight in kilogram divided by height in $\mathrm{m}^{2}$. Approximately 1.6 billion adults worldwide are overweight (BMI 25-30 kg/m2) and at least 400 million were obese (BMI $>30 \mathrm{~kg} / \mathrm{m} 2$ ) in 2005. These figures are expected to rise to 2.3 billion and 700 million respectively, by 2015. The prevalence of obesity is relatively low in Asian countries with $4 \%$ of Chinese and $0.5 \%$ of Indian women noted to be obese ${ }^{5}$.

Obesity in women has shown to increase time to conception 6 . The relative risk of anovulatory infertility is 2.7 (95\% CI, 2.0-3.7) in women with $\mathrm{BMI} \geq 32 \mathrm{~kg} / \mathrm{m}^{2}$ at age 187 . While in ovulatory but subfertile women the chance of spontaneous conception decreases by $5 \%$ for each units increase in the $\mathrm{BMI}^{8}$.

AIMS AND OBJECTIVES: This was a prospective study to investigate the relationship between weight reduction and its effect on fertility in obese / overweight women.

MATERIALS AND METHODS: A total of 62 obese female with body mass index $>25 \mathrm{~kg} / \mathrm{m}^{2}$ with menstrual dysfunction aged 20-45 years were selected for this study. Women who presented with infertility of $4.5 \pm 3$ years duration were included. The study was conducted for 2 years between June 2011 to May 2013 at Calcutta National Medical College and Hospital in the department of Obstetrics and Gynecology. 
Inclusion criteria: Obesity, infertility, menstrual irregularity without any thyroid and prolactin abnormality. In this group of 62 women, 7 had features of polycystic ovaries in pelvic ultrasonography.

After giving weight reduction treatment by dietary restriction and exercise, patients had been advised to report after 6 weeks in the outpatient department for follow up. The diet was restricted to only 1200 calories / day. Approximate 1200 calories intake was divided into 5 meal timings. An early morning snacks (60 calories), Breakfast (150 calories), Lunch (500 calories), an afternoon snack (120 calories) and Dinner (470 calories).

In every follow up visit history was taken to note any subjective improvement, clinical examination was done to note reduction in body mass index or only clinical improvement (positive pregnancy test).

\section{RESULTS:}

\begin{tabular}{|c|c|c|}
\hline Age & No. of Patients & Percentage \\
$20-25$ yrs. & 14 & $22.58 \%$ \\
$25-35$ yrs. & 30 & $48.38 \%$ \\
$35-45$ yrs. & 18 & $29.03 \%$ \\
\hline
\end{tabular}

Table I: Demographic Variation $(\mathrm{n}=62)$

\begin{tabular}{|c|c|c|}
\hline Body Mass Index & & \\
$25-29.9$ (overweight) & 20 & 32.25 \\
30 and above (obese) & 42 & 67.74 \\
\hline
\end{tabular}

Table II: Distribution of patients $(\mathrm{n}=62)$ according to body mass index $\left(\mathrm{kg} / \mathrm{m}^{2}\right)$

6 patients out of 62 obese patients did not follow the weight reduction treatment schedule. Rest 56 patients followed the treatment scheduled. The 6 patients who did not follow the treatment schedule, failed to show any clinical improvement regarding body mass index and fertility.

\begin{tabular}{|l|c|c|}
\hline \multicolumn{1}{|c|}{ Fertility } & No. of patient & \% \\
\hline Fertile & 20 & 42.55 \\
\hline Primary infertility & 12 & 22.53 \\
\hline Secondary infertility & 15 & 31.91 \\
\hline
\end{tabular}

Table III: Fertility status of the patient

\begin{tabular}{|l|c|c|}
\hline \multicolumn{1}{|c|}{ Result of wt. reduction } & No. of patient & \% \\
\hline BMI 30 and above & 16 & 28.57 \\
\hline BMI $25-29.9 \mathrm{~kg} / \mathrm{m} 2$ & 15 & 26.78 \\
\hline BMI $20-25$ & 25 & 44.64 \\
\hline
\end{tabular}

Table IV: Effect of weight reduction schedule on body mass index $(n=56)$ 
16 patients with pretreatment body mass index 30 and above and 5 patients with pretreatment body mass index 25-29.9 did not respond to treatment schedule and remained obese. Out of 56 patients who followed the weight reducing schedule, $35(62.5 \%)$ patients reduced their weight with and average reduction of 7-10 kgs of body weight.

\begin{tabular}{|c|c|c|}
\hline $\begin{array}{c}\text { Number of patients to conceive } \\
\text { after weight reduction schedule }\end{array}$ & Number of infertile patients & Percentage \\
\hline 7 & 27 & $25.75 \%$ \\
\hline
\end{tabular}

Table V: Number of patients regained fertility after weight reduction schedule

Fertility regained in 7 patients out of 27 infertile patients after weight reduction.

Estimated success probability is 0.2592 . Estimated variant of success probability is $7.11 \times 10^{-3}$ and the $95 \%$ confidence interval for $\mathrm{P}(0.094,0.424$ i.e. with $95 \%$ confidence we can say that $\mathrm{p}$ will lie between 0.094-0.424).The result is statistically significant.

\begin{tabular}{|l|c|c|}
\hline \multicolumn{1}{|c|}{ Reduction of BMI after Rx } & No of patient & Percentage (\%) \\
\hline $\begin{array}{l}\text { Pretreatment BMI 30 and above reduced } \\
\text { after treatment to BMI 25-29.9 }\end{array}$ & 2 & 28.57 \\
\hline $\begin{array}{l}\text { Pretreatment BMI 30 and above reduced } \\
\text { after treatment to BMI 20-25 }\end{array}$ & 4 & 57.14 \\
\hline $\begin{array}{l}\text { Pretreatment BMI 25-29.9 reduced } \\
\text { after treatment to BMI 20-25 }\end{array}$ & 1 & 14.28 \\
\hline \multicolumn{2}{|c|}{$\begin{array}{l}\text { Table VI: Distribution of patients who regained fertility } \\
\text { after weight reduction (n=7) according to BMI }\end{array}$} \\
\hline
\end{tabular}

DISCUSSION: Obesity is an excess of body fat. It may be hypertrophic, hyperplastic or a combination of both. Fat cells or adipocytes have aromatase activity. Obese women have excess number of fat cells in which extraglandular aromatization of androgen to estrogen occurs. They also have lower circulating levels of Sex Hormone Binding Globulin (SHBG) which allows a large proportion of free androgen to be converted to estrone. Increased estrone trigger an increase in Luteinizing Hormone (LH) with consequent ovarian hyperstimulation, leading to increased testosterone and anovulatory cycles. The decrease in SHBG also allows an increase in free androgen levels.

Several studies show that weight reduction induced by exercise and low calorie diets improves hyperandrogenemia, insulin resistance, and menstrual dysfunction10. Many authors recommended weight loss as the best, cheapest and cause related therapy of infertile, obese women. Commonly these women do not respond easily to the usual treatment with antiestrogens and gonadotropins.

In our study, after weight reduction $25.72 \%$ of patients conceived subsequently. At the end of our study majority of the patients were still continuing their pregnancies and some had live births. Our study results are less when compared to Bates and Whitworth study with $77 \%$ pregnancy rates after weight reduction of $15 \%$ of boy weight ${ }^{9}$. But has similar results like Hollmann et al study which showed $29 \%$ pregnancy rates ${ }^{10}$. 
Obese women often have a decreased reproductive potential, as evidenced by menstrual disturbances, anovulation, time to conception, poor response to ovulation induction and reduced pregnancy outcome ${ }^{11}$. The imbalance in the estrogens and androgens cause irregular ovulation and anovulation. Obesity accounts for infertility $15-20 \%$ of infertile patients. A poor quality of ova even in presence of ovulation leads to subfertility. Obese women require higher doses of drugs and prolong treatment and still do not respond to fertility treatment satisfactorily.

The results of this study support the hypothesis that it is possible to improve fertility rates in obese or overweight women with lifestyle modification by using a lifestyle program that sets realistic weight loss and exercise goals. Subjects were able to sustain hormonal imbalances, menstrual irregularities and regain ovulation to achieve pregnancy. Weight loss in these subjects resulted in resumption of ovulation and correction of the hyperandrogenemia.

Abdominal obesity is associated with increased level of insulin, chronic hyperinsulinemia causes increased ovarian androgen production, increased LH secretion from pituitary and decreased sex hormone binding globulin production leading to increase in free circulating androgen, and this androgen becomes aromatized by fat cells to estrogen leading to chronic hyperestrogenic environment 12 .

Even of 5\% decrease in weight improves fertility in obese PCOS by decreasing fasting insulin levels and increased frequency of ovulation.

Norman RJ and Clark AM 13 during their study regarding obesity and reproductive disorder, found obesity has significant consequences for the reproductive system, depending upon the amount and distribution of body fat. Obesity contributes to menstrual disorders, infertility, miscarriage, poor pregnancy outcome, impaired fetal well-being and diabetes mellitus. Central adiposity is particularly important in clinical sequlae associated with an increased body mass index. They showed that weight loss has marked effects on improving the menstrual cycle and promoting spontaneous ovulation and fertility. Results indicate that fertility is improved through exercise and sensible eating pattern when conducted in a group environment. The mechanism is probably associated with changes in sensitivity to insulin ${ }^{14}$.

CONCLUSION: Obesity in women has impacts on fertility and fertility treatment. Increase in body mass index reduces the chance of conception in women. Obesity is associated with lower fertilization rates, poor quality embryos and higher miscarriage rates. Weight loss in these women improves their reproductive outcomes; however, in order for this to be effective it has to be gradual and sustained.

\section{REFERENCE:}

1. Kopelman PG, Pilkngton TRE, White N and Jeffcoate SL. Abnormal sex steroid secretion and binding in massively obese women. Clin Endocrinol (Oxf) 1980;12: 363-369

2. Hershcopf RJ and Bradlow HL. Obesity diet endogenous estrogens and the risk of hormone sensitive cancer. Am J Clin Nutr 1987;45: 283-289

3. Balen AH, Conway GS, Katsas G et al. Polycystic ovary syndrome: the spectrum of the disorder in 1741 patients. Hum Reprod 1995;10: 2107-2111

4. Pregnancy outcomes in overweight and obese women - Internet. Med. Stanford School of Medicine Treatment. Med.standford.edu/clinicaltrials.detail.do study Id 7603, page 1-5 
5. Prentice AM. The emerging epidemic of obesity in developing countries. Int J Epidemiol 2006; 35: 93-9.

6. Nohr EA, Vaeth M, Rasmussen S, Ramlau-Hansen $\mathrm{CH}$, Olsen J. Waiting time to pregnancy according to maternal birthweight and pre-pregnancy BMI. Hum Reprod 2009; 24: 226-32.

7. Rich-Edwards JW, Goldman MB, Willett WC, Hunter DJ, Stampfer MJ, Colditz GA, et al. Adolescent body mass index and infertility caused by ovulatory disorder. Am J Obstet Gynecol 1994; 171: 171-7.

8. Van der Steeg JW, Steures P, Eijkemans MJ, Habbema JD, Hompes PG, Burggraaff JMl. Obesity affects spontaneous pregnancy chances in subfertile, ovulatory women. Hum Reprod 2008;23: 324-8.

9. Holte J, Bergh T, Berne C, Wide L, Lithell H. Restored insulin sensitivity but persistently increased early insulin secretion after weight loss in obese women with polycystic ovary syndrome. J Clin Endocrinol Metab. 1995;80: 2586-2593

10. Bates GW, Whitworth NS. Effect of body weight reduction on plasma androgens in obese, infertile women. Fertil Steril 1982; 38: 406.

11. Hollmann M, Runnebaum B, Gerhard I. Effects of weight loss on the hormonal profile in obese, infertile women. Hum Reprod 1996 Sep; 1884-91.

12. Hamilton Fairley D, Kiddy D, Watson H, Peterson C, Franks S. Pregnancy outcome in women with polycystic ovary syndrome treated with low dose gonadotropin. Br J Obstet Gynecol 1992;99: 128-131

13. Norman RJ, Clerk AM. Obesity and reproductive disorders: a review. Reprod Fertil Dev 1998;10(1): 55-63

14. Sneed ML, Uhler ML, Grotjan HE, Rapisarda JJ. Lederer KJ, Beltsos AN. Body Mass Index: Impact on IVF Success appears age related. Hum Reprod 2008;23: 1835-9.

\section{AUTHORS:}

1. Sucheta Mukherjee

2. Lovely Agarwal

3. Mrinal Kanti Biswas

4. Debilina Roy

\section{PARTICULARS OF CONTRIBUTORS:}

1. Assistant Professor, Department of Obstetrics and Gynaecology, Bankura Sammilani Medical College.

2. RMO cum Clinical Tutor, Department of Obstetrics and Gynaecology, National Medical College.

3. Assistant Professor, Department of Obstetrics and Gynaecology, National Medical College.
4. Junior Resident, Department of Obstetrics and Gynaecology, Bankura Sammilani Medical College.

\section{NAME ADDRESS EMAIL ID OF THE CORRESPONDING AUTHOR:}

Dr. Sucheta Mukherjee,

27/T, R.K. Street,

P.O. Uttarpara, Dt. Hooghly,

PIN - 712258, (WB), India.

E-mail: suchetamukherjee76@rediffmail.com

Date of Submission: 30/12/2013.

Date of Peer Review: 31/12/2013.

Date of Acceptance: 16/01/2014.

Date of Publishing: 30/01/2014. 